\title{
PENGAWASAN ORANG ASING TERHADAP PEMBERLAKUAN BEBAS VISA KUNJUNGAN PADA KANTOR IMIGRASI KELAS 1 KHUSUS NGURAH RAI
}

\author{
Ni Made Putri Kartika Jati, I Wayan Arthanaya, I Nyoman Sutama \\ Fakultas Hukum Universitas Warmadewa, Denpasar-Bali, Indonesia \\ putrikartika933@yahoo.co.id
}

\begin{abstract}
Abstrak
Bebas visa kunjungan dapat diberikan di beberapa tempat pemeriksaan imigrasi yang tersebar di seluruh Indonesia. Tempat pemeriksaan imigrasi dilaksanakan di Bandara Internasional I Gusti Ngurah Rai. Berkaitan dengan implementasi kebijakan bebas visa kunjungan, adapun upaya-upaya yang dilakukan jajaran imigrasi yaitu meningkatkan jumlah personil, pengawasan pendaratan dan izin masuk dari orang asing, pengawasan penggunaan izin tinggal oleh orang asing di berbagai tempat terutama di bidang pariwisata maupun diberbagai tempat hiburan. Tujuan penelitian ini adalah untuk menjelaskan pemberlakuan kebijakan bebas visa di Kantor Imigrasi Kelas I Khusus Ngurah Rai dan menjelaskan akibat hukum yang ditimbulkan dari kebijakan bebas visa di Kantor Imigrasi Kelas I Khusus Ngurah Rai. Metode penelitian menggunakan deksriptif empiris. Sumer data yang digunakan adalah bahan hukum primer yaitu data pokok yang diperoleh dari peraturan Undang-Undang, sedangkan bahan hukum sekunder yaitu data yang diperoleh dari pendapat para ahli, jurnal penelitian, buku literatur, artikel ataupun majalah serta data lain yang diperoleh dari beragam sumber yang berhubungan dengan masalah yang menjadi pokok bahasan dalam penelitian ini. Hasil penelitian menunjukkan bahwa Pemberlakuan kebijakan bebas visa di Kantor Imigrasi Kelas I Khusus Ngurah Rai sudah sesuai dengan peraturan terbaru yaitu Peraturan Presiden Republik Indonesia Nomor 21 Tahun 2016 tentang Bebas Visa Kunjungan, selanjutnya akibat hukum yang ditimbulkan dari kebijakan bebas visa di Kantor Imigrasi Kelas I Khusus Ngurah Rai adalah sesuai fungsi imigrasi yaitu melakukan seleksi terhadap setiap maksud kedatangan orang asing, terdapat beberapa kasus pelanggaran hukum yang dapat lebih mudah masuk ke Indonesia seperti pekerja asing yang bekerja tanpa izin lengkap di Indonesia.
\end{abstract}

Kata Kunci: Bebas Visa; Imigrasi; Pengawasan

\begin{abstract}
Free visit visas can be granted at several immigration checkpoints throughout Indonesia. Immigration checkpoints are carried out at I Gusti Ngurah Rai International Airport. With regard to the implementation of the visa-free visit policy, there are efforts made by the immigration ranks, namely increasing the number of personnel, monitoring the landing and entry permits of foreigners, monitoring the use of residence permits by foreigners in various places, especially in the field of tourism and various entertainment venues. The purpose of this study is to explain the application of the visa-free policy at the Ngurah Rai Special Class I Immigration Office and to explain the legal consequences of the visa-free policy at the Ngurah Rai Class I Special Immigration Office. The research method uses an empirical description. Data sources used are primary legal materials, namely basic data obtained from statutory regulations, while secondary legal materials are data obtained from expert opinions, research journals, literature books, articles or magazines and other data obtained from various sources related to the problems that are the subject of this research. The results showed that the application of the visa-free policy at the Ngurah Rai Class I Special Immigration Office was in accordance with the latest regulations, namely the Presidential Regulation of the Republic of Indonesia Number 21 of 2016 concerning Visit Visa Free, further legal consequences resulting from the visa-free policy at the Special Class I Immigration Office. Ngurah Rai is in accordance with the function of immigration, which is to select every intention of the arrival of foreigners, there are several cases of lawlessness that can more easily enter Indonesia, such as foreign workers who work without complete permits in Indonesia.
\end{abstract}

Keywords: Visa Free; Immigration; Supervision

\section{PENDAHULUAN}

Negara Kesatuan Republik Indonesia adalah negara kepulauan yang berada dijalur perlintasan laut internasional dan dihubungkan dua samudra yaitu samudra Pasifik dan samudra Indonesia juga diapit oleh dua benua yaitu benua Asia dan benua Australia. Indonesia dengan letak geografisnya yang sedemikian rupa menjadikannya sebagai jalan silang bagi jalur perlintasan pelayaran dan perdagangan Internasional. Dalam hal peningkatan perekonomian dalam bidang pariwisata, maka pemerintah 
dalam bidang keimigrasian memberlakukan kebijakan bebas visa kunjungan singkat (BVKS) sesuai dengan Keputusan Presiden RI Nomor 15 Tahun 1983 tanggal 9 Maret 1983 tentang kebijakan pengembangan kepariwisataan pada awalnya bertujuan untuk mendorong pertumbuhan pariwisata. Bentuk kebijakan ini merupakan pembebasan dari kewajiban memiliki visa untuk melakukan perjalanan ke Indonesia bagi Negara-negara di ASEAN.

Imigrasi merupakan stakeholder yang sangat berhubungan langsung dengan pariwisata khususnya wisatawan mancanegara karena Imigrasi merupakan lalu lintas orang yang masuk ataupun keluar dari wilayah Indonesia dan pengawasannya juga untuk menjaga tegaknya kedaulatan Negara Republik Indonesia sesuai dengan yang tercantum dalam Undang-Undang Nomor 6 Tahun 2011 pasal 1. Perlintasan dan pengawasan sangat penting terhadap kegiatan masuk atau keluar seseorang serta keberadaan dan kegiatan orang Asing yang berada di Indonesia (Wirasto et al., 2016). Kegiatan orang Asing di Indonesia salah satunya adalah berwisata menjadi fokus utama Imigrasi sebagai stakeholder pariwisata, sehingga dalam menjalankan tugasnya dikeluarkan beberapa kebijakan untuk mendukung pariwisata.

Kebijakan Keimigrasian yang mendukung pariwisata meliputi pembebasan kewajiban memiliki visa bagi beberapa negara yang membawa manfaat dengan memperhatikan asas timbal balik yang dimana pembebasan visa hanya diberikan kepada Orang Asing dari negara yang juga memberikan pembebasan visa kepada Warga Negara Indonesia. Pembebasan kewajiban memiliki visa bagi beberapa negara tersebut dikeluarkan melalui Peraturan Presiden Nomor 18 Tahun 2003 tentang Bebas Visa Kunjungan Singkat yang diberikan kepada 15 negara (Setiadi \& Afrizal, 2019). Peraturan presiden dengan membebaskan 15 negara tentu dapat menarik minat wisatawan dari negara tersebut untuk berwisata di Indonesia. Selanjutnya pemberian bebas visa untuk kepentingan pariwisata pun dikeluarkan kembali pada tahun 2015 melalui Peraturan Presiden Nomor 69 Tahun 2015 dikeluarkan kebijakan pembebasan kewajiban memiliki visa khusus untuk tujuan wisata kepada 30 negara dari subyek Visa Kunjungan Saat Kedatangan (Visa On Arrival).

Bebas visa kunjungan ini diberlakukan pembatasan terhadap tempat masuk dan keluar wilayah Indonesia. Orang Asing yang memperoleh fasilitas bebas visa kunjungan hanya dapat masuk atau pun keluar pada 9 tempat pemeriksaan imigrasi. Tentunya pembatasan tersebut menyebabkan banyak kendala yang terjadi ditambah lagi informasi mengenai penggunaan fasilitas bebas visa kunjungan tersebut masih kurang. sehingga pada 18 september 2015, presiden Jokowidodo telah menandatangani Peraturan Presiden (Perpres) Nomor 104 Tahun 2015 tentang Perubahan Atas Perpres Nomor 69 Tahun 2015 tentang Bebas Visa Kunjungan. Perpres ini dikeluarkan dengan pertimbangan untuk meningkatkan perekonomian nasional, khususnya peningkatan jumlah kunjungan wisatawan. Jumlah negara yang mendapatkan bebas visa kunjungan pun mengalami penambahan. Setidaknya, terdapat 75 negara yang warganya dibebaskan dari visa kunjungan. Tidak hanya dari jumlah negara yang dibebaskan dari kewajiban memiliki visa ketentuan pembatasan Tempat Pemeriksaan Imigrasi yang dapat memberi izin masuk dan keluar dengan bebas visa kunjungan pun dihapuskan.

Selanjutya 6 bulan setelah dikeluarkannya Nomor 104 Tahun 2015 tentang Perubahan Atas Perpres Nomor 69 Tahun 2015 tentang Bebas Visa Kunjungan, dikeluarkan kembali kebijakan yang menambah jumlah negara yang mendapat fasilitas bebas visa kunjungan yaitu total 169 negara. Keterbukaan Indonesia yang sangat bebas dan luas terhadap Orang Asing membawa dampak positif ataupun negatif bagi Indonesia, oleh sebab itu peran fungsi Keimigrasian sangat diperlukan (Armansyah., dkk., 2019).

Dengan adanya kebijakan bebas visa tentu memberikan pengaruh yang besar terhadap kunjungan wisatawan mancanegara ke Bali khususnya. Dengan optimisme tahun ini pemerintah menargetkan kunjungan wisman sebanyak 6.5 juta kunjungan. Ini lebih besar dari rata-rata kenaikan target sebesar 500 ribu kunjungan tiap tahunnya. Mengingat tiap tahun target kunjungan wisman selalu mencapai target. Kunjungan warga Negara Asing ke pulau Bali justru meninggalkan beberapa masalah salah satunya adalah tingkat pelanggaran keimigrasian. Hal ini tentu merugikan Negara bukan hanya dalam bidang perekonomian namun juga keamanan Negara. Dengan adanya kebijakan bebas visa yang diperuntukan bagi orang asing, maka hal ini tentu saja dapat menimbulkan persoalan yang terkait dengan pengimplementasian, pengawasan, keamanan, intensitas keluar masuknya orang asing, tingkat pelanggaran yang terjadi yang diakibatkan dengan adanya Bebas Visa dan juga sumber daya keimigrasian yang ada, selain itu beberapa Negara kecil yang mendapatkan kebijakan bebas visa ini 
juga tidak memberikan keuntungan dengan asas timbal balik/resiprokal terhadap Negara Indonesia, hal ini hanya memberikan keuntungan kepada Negara subjek penerima bebas visa.

Bebas visa kunjungan adalah visa yang diberikan kepada orang asing pada saat tiba di Indonesia tanpa membayar visa dengan jangka waktu 30 hari dan tidak dapat diperpanjang. Bebas visa kunjungan dapat diberikan di beberapa Tempat Pemeriksaan Imigrasi (TPI) yang tersebar di seluruh Indonesia. Kantor Imigrasi Kelas I Khusus Ngurah Rai sendiri membawahi sebuah Tempat Pemeriksaan Imigrasi yaitu Bandara Internasional I Gusti Ngurah Rai, dimana Bandara ini merupakan salah satu dari 5 (lima) Tempat Pemeriksaan Imigrasi terbesar di Indonesia. TPI I Gusti Ngurah Rai juga merupakan TPI dengan jumlah pengguna bebas visa kunjungan terbesar di Indonesia. Hal ini disebabkan karena Bali merupakan destinasi liburan favorit bagi turis-turis mancanegara. Keindahan alam serta budaya yang masih sangat kental di Bali menjadi daya tarik tersendiri bagi wisatawan asing untuk menghabiskan waktu liburannya. Turis-turis yang datang ke Bali kebanyakan berasal dari wilayah Eropa, Asia dan Australia, dimana wisatawan dari Australia merupakan wisatawan mayoritas yang datang ke Bali. Namun tidak sedikit dari wisatawan tersebut yang akhirnya tinggal menetap di Bali, bekerja bahkan berkeluarga dengan warga negara Indonesia.

Ada beberapa penelitian terdahulu telah melakukan penelitian yang relevan dengan penelitian ini yaitu Prayulianda \& Antikowati, (2019); Muhlisa \& Roisah, (2020) mengkaji tentang penegakan hukum keimigrasian terhadap penyalahgunaan visa izin tinggal kunjungan lewat batas waktu (overstay) pada warga Negara Asing. Penelitian lain mengkaji tentang penegakan hukum terhadap warga negara asing (wna) yang melanggar izin tinggal (overstay) (Setiawati, 2015). Sekalipun sudah banyak penelitian yang mengkaji tentang keimigrasian, namun sampai sekarang masih terjadi penyalah gunaan bebas visa, sehingga penelitian ini dilakukan bertujuan untuk mengetahui pemberlakuankebijakan bebas visa di Kantor Imigrasi Kelas I Khusus Ngurah Rai serta untuk mengetahui akibat hukum yang ditimbulkan dari kebijakan bebas visa di Kantor Imigrasi Kelas I Khusus Ngurah Rai.

\section{METODE PENELITIAN}

Jenis penelitian yang digunakan adalah penelitian hukum normatif dan penelitian ini bersifat deskripstif analitis. Deskriptif kualitatif adalah menggambarkan secara tepat, sifat individu, suatu gejala, keadaan atau kelompok tertentu (Koentjaraningrat, 2007); (Soekanto, 2009). Deskriptif analitis bertujuan untuk menggambarkan suatu peraturan hukum dalam konteks teori-teori hukum dan pelaksanannya, serta menganalisis fakta tentang perubahan yang terjadi akibat pemberian Bebas Visa Kunjungan dengan pendekatan langsung pada Kantor Imigrasi Kelas 1 Khusus Ngurah Rai dan Tempat Pemeriksaan Imigrasi Bandara Internasional Ngurah Rai. Bahan hukum yang digunakan adalah bahan hukum primer yaitu data pokok yang diperoleh dari peraturan Undang -Undang Nomor 6 Tahun 2011 tentang Keimigrasian. Undang-Undang Nomor 10 Tahun 2009 tentang, selanjutnya menggali data dari Petugas Imigrasi di Kantor Imigrasi Kelas 1 Khusus Ngurah Rai dan Pejabat Imigrasi di Tempat Pemeriksaan Imigrasi Bandar Udara Internasional Ngurah Rai, sedangkan bahan hukum sekunder yaitu data yang diperoleh dari pendapat para ahli, jurnal penelitian, buku literatur, artikel ataupun majalah serta data lain yang diperoleh dari beragam sumber yang berhubungan dengan masalah yang diteliti. Setelah data terkumpul, dianalisa dengan meminimalisasi bahan, memaparkan dan kemudian dianalsia dengan menggunakan analisa hukum dengan menggunakan logika hukum deduktif dan induktif (Waluyo, 2002)

\section{HASIL DAN PEMBAHASAN}

\section{Pemberlakuan Kebijakan Bebas Visa di Kantor Imigrasi Kelas I Khusus Ngurah Rai}

Pelayanan keimigrasian termasuk dalam pelayanan publik, maka dari itu pengawasan Orang Asing di Wilayah Kerja Kantor Imigrasi Kelas I Khusus Ngurah Rai dilakukan kepada seluruh warga negara asing yang berkunjung ke Indonesia. Sesuai dengan Undang-Undang Nomor 25 Tahun 2009 Pelayanan publik ialah suatu kegiatan atau rangkaian kegiatan dengan tujuan untuk pemenuhan kebutuhan pelayanan berdasarkan dengan peraturan perundang-undangan bagi setiap Warga Negara dan penduduk atas barang, jasa, atau pelayanan administratif yang disediakan oleh penyelenggara pelayanan publik.

Direktorat imigrasi berperan sebagai pendukung kebijakan permerintah dalam meningatan kesejahterahaan masyarakat salah satunya tercermin dengan terbitnya Peraturan Presiden Nomor 104 
Tahun 2017 tentang Bebas Visa kunjungan sebagai wujud dukungan Direktorat Imigrasi kepada kementerian pariwisata dalam mengembangan jumlah wisatawan mancanegara yang berunjung ke Indonesia. Penyelenggaraa pelayanan publik dalam pelayanan keimgrasian ini diselenggarakan salah satunya oleh bidang lalintuskim (lalu lintas dan status keimigrasian) pada Kantor Imigrasi. Pelayanan keimigrasian diberikan kepada WNI maupun WNA. Pelayanan keimigrasian terhadap Warga Negara Indonesia meliputi pemberian paspor, surat perjalanan laksana paspor, pas lintas batas, tanda keluar dan tanda masuk di tempat pemeriksaan Imigrasi dan penerimaan penyampaian pernyataan memilih kewarganegaraan bagi anak berkewarganegaraan ganda terbatas sesuai pasal 6 Undang- Undang Nomor 12 Tahun 2006 tentang Kewarganegaraan Republik Indonesia (Hamidi, 2015).

Sementara pelayanan terhadap Orang Asing meliputi pemberian visa, izin tinggal, izin masuk kembali, smart card, kartu APEC/ABTC, surat keterangan keimigrasian dalam rangka pewarganegaraan atau prnyataan untuk menjadi Warga Negara Indonesia sesuai Undang- Undang Nomor 12 Tahun 2006, surat keterangan (affidavit) kewarganegaraan ganda terbatas, penerimaan penyampaian pernyataan memilih kewarganegaraan bagi anak berkewarganegaraan ganda terbatas sesuai pasal 6 Undang-Undang Nomor 12 Tahun 2006 serta tanda keluar dan tanda masuk di tempat pemeriksaan imigrasi. Dengan adanya Kebijakan bebas visa kunjungan memberikan dampak yang sangat signifikan bagi bidang pelayanan keimigrasian bagi Orang Asing. Pelayanan bagi Orang Asing yang salah satunya yaitu perpanjangan izin tinggal dengan adanya fasilitas bebas visa kunjungan maka jumlah pembelian Visa On Arrival mengalami penurunan. Penurunan pembelian Visa on Airrival ini sangat drastis karena negara yang diberikan fasilitas Bebas Visa Kunjungan sebagian besar merupakan negara-negara subyek dari Visa On Arrival.

Berdasarkan wawancara dengan petugas pendaratan di tempat pemeriksaan imigrasi pada Bandara Klas I Ngurah Rai menyatakan dalam sehari yang biasanya Petugas Pendaratan dapat menerima Visa On Arrival sebanyak 400 voucher VOA kini hanya 50 voucher VOA. Dari laporan rekonsiliansi VOA Imigrasi dengan Bank Rakyat Indonesia (BRI) Tahun 2016 pada Kantor Imigrasi Klas 1 Khusus Klas I Ngurah Rai voucher VOA yang terjual sebanyak 1.183.721. Sedangkan pada tahun 2017 penjualan voucher VOA sebanyak 905.430. Penurunan terhadap Visa Kunjungan Saat Kedatangan juga dialami Kantor Imigrasi Klas 1 Khusus Ngurah Rai. Kantor Imigrasi Klas 1 Khusus Ngurah Rai yang terletak di Bali sebagai tujuan utama wisatawan mancanegara juga mengalami penurun penggunaan serta perpanjangan visa kunjungan saat kedatangan. Berikut merupakan data mengenai perpanjangan visa kunjungan saat kedatangan di Kantor Imigrasi Klas I Ngurah Rai:

Tabel 1.

Perpanjangan Visa Kunjungan Saat Kedatangan Di Kantor Imigrasi Klas I Ngurah Rai

\begin{tabular}{|c|c|c|c|}
\hline No. & Kegiatan & 2016 & 2017 \\
\hline 1. & Pemberian VKSK & 3.044 .292 & 2.011 .857 \\
\hline 2. & Perpanjangan VKSK & 27.258 & 25.742 \\
\hline
\end{tabular}

Sumber: Statistik Kegiatan Keimigrasian Kantor Imigrasi Klas 1 Khusus Ngurah Rai

Tahun 2016-2017

Berdasarkan data tersebut terjadi penurunan jumlah permohonan perpanjangan izin tinggal Visa Kunjungan Saat Kedatangan sebanyak 5.5\%. Jadi dapat disimpulkan setelah diberlakukannya kebijakan Bebas Visa Kunjungan berdampak pada fungsi keimigrasian pelayanan publik terhadap WNA yaitu penurunan jumlah permohonan perpanjangan izin tinggal visa kunjungan saat kedatangan. Penurunan jumlah pembelian VOA ini beraibat PNBP Diretorat Jenderal Imigrasi mengalami penurunan sebesar $37 \%$.

\section{Akibat Hukum yang Ditimbulkan dari Kebijakan Bebas Visa di Kantor Imigrasi Kelas I Khusus Ngurah Rai}

Akibat hukum yang ditimbulkan dari kebijakan bebas visa di kantor imigrasi kelas I khusus Ngurah Rai adalah dimana sesuai salah satu fungsi imigrasi yaitu melakukan seleksi terhadap setiap maksud kedatangan Orang Asing, terdapat beberapa kasus pelanggaran hukum yang dapat lebih mudah masuk ke Indonesia seperti pekerja asing yang bekerja tanpa izin lengkap di Indonesia. Salah satu contoh kasus di Bali adalah dimana banyak terjadinya tour guide asal Tiongkok yang bekerja secara illegal di 
Bali dalam menghandle beberapa tamu asal Tiongkok saat berlibur di Bali. Berdasarkan wawancara terhadap Bapak Doni Alfisahrin selau Kabid Lalintuskim Kantor Imigrasi Kelas I Khusus Ngurah Rai mengatakan bahwa pihak imigrasi Ngurah Rai bekerja sama dengan dinas pariwasata dan dinas tenaga kerja Provinsi Bali sering melakukan inspeksi mendadak pada spot pariwisata tertentu seperti Pura Uluwatu, Pura Tanah Lot dan Pura Besakih untuk melakukan pengecekan dari beberapa tour guide asal negeri Tiongkok yang bekerja secara illegal di Bali untuk memandu wisata dari tamu asal Tiongkok. Konsekuensi hukumnya adalah dimana pekerja tersebut akan dideportasi kemabli ke Tiongkok, serta pihak pengelola usaha perjalanan wisata akan dikenakan sanksi administrative seperti denda.

Berdasarkan hasil wawancara tersebut, dapat dilihat bahwa salah satu akibat hukum dari kebijakan bebas visa di kantor imigrasi kelas I Khusus Ngurah Rai adalah mudahnya terjadi pelanggaran terhadap unsur-unsur keimigrasian seperti melakukan kegiatan bisnis dengan tujuan awal untuk berwisata, hingga dapat merugikan pendapatan daerah akibat pajak yang tidak dibayarkan oleh pekerja asing illegal tersebut dan dapat mengurangi lapangan pekerjaan dari pekerja local bali yang sudah memiliki izin untuk beroperasi sebagai pemandu wisata.

Selain masalah tenaga kerjaan, terjadi pula peningkatan tingkat kriminalitas dari Warnga Negara Asing yang berkunjung ke Bali. "Ada sejumlah wisman yang dideportasi dan ada dua-tiga wisman di wilayah administrasi Imigrasi Ngurah Rai yang akan dideportasi. Bahkan ada yang mau dideportasi tapi tak memegang paspor. Jadi harus menunggu paspornya ada, baru bisa dideportasi, "Ada sejumlah wisman yang dideportasi dengan asalan melakukan tindak criminal seperti pencurian dan pengedaran narkotika. Selain itu kasus terkini terjadi beberapa perusakan sarana umum yang dilakukan oleh Bahkan ada yang mau dideportasi tapi tak memegang paspor. Jadi harus menunggu paspornya ada, baru bisa dideportasi.

\section{SIMPULAN DAN SARAN}

\section{Kesimpulan}

Berdasarkan hasil analisis data, dapat disimpulkan bahwa Pemberlakuan kebijakan bebas visa di Kantor Imigrasi Kelas I Khusus Ngurah Rai sudah sesuai dengan peraturan terbaru yaitu Peraturan Presiden Republik Indonesia Nomor 21 Tahun 2016 tentang Bebas Visa Kunjungan. Terdapat 169 negara di seluruh dunia yang warga negaranya dapat berkunjung ke Indonesia tanpa menggunakan visa, selanjutnya akibat hukum yang ditimbulkan dari kebijakan bebas Visa di Kantor Imigrasi Kelas I Khusus Ngurah Rai adalah sesuai fungsi imigrasi yaitu melakukan seleksi terhadap setiap maksud kedatangan orang asing, terdapat beberapa kasus pelanggaran hukum yang dapat lebih mudah masuk ke Indonesia seperti pekerja asing yang bekerja tanpa izin lengkap di Indonesia.

\section{Saran}

Dari hasil penelitian di atas, maka dapat disarankan kepada Pemerintah Pusat Republik Indonesia hendaknya mengkaji ulang setiap Negara yang diberikan fasilitas bebas visa di Indonesia. Karena terdapat beberapa negara yang memiliki data kunjungan rendah namun tetap mendapatkan kebijakan visa gratis. Selanjutnya Pihak Imigrasi Kelas I Ngurah Rai Bali hendaknya memiliki kerjasama yang baik dengan beberapa Dinas terkait seperti Dinas Tenaga Kerja agar mengurangi dampak negatif yang terjadi di Bali seperti pekerja asing yang bekerja tanpa izin lengkap di Industri Pariwisata Bali.

\section{DAFTAR PUSTAKA}

Armansyah, A. A., Agis, A., \& Hidjaz, M. K. (2019). Penegakan Hukum Keimigrasian Terhadap Warga Negara Asing Anak Buah Kapal (ABK) Tangkap Ikan Secara Ilegal. Pleno Jure, 9(2), 17-36.

Hamidi, J. (2015). Hukum Keimigrasian bagi Orang Asing di Indonesia. Sinar Grafika.

Koentjaraningrat. (2007). Metode-Metode Penelitian Masyarakat. Prenada Media.

Muhlisa, A. N., \& Roisah, K. (2020). Penegakan Hukum Keimigrasian Terhadap Penyalahgunaan Visa Izin Tinggal Kunjungan Lewat Batas Waktu (Overstay) Pada Warga Negara Asing. Jurnal Pembangunan Hukum Indonesia, 2(2), 145-157.

Prayulianda, H. A., \& Antikowati. (2019). Pengawasan Warga Negara Asing Penerima Bebas Visa Kunjungan dalam Perspektif Hukum Kewarganegaraan. Lentera Hukum, 6(1), 141-150.

Setiadi, W., \& Afrizal, R. A. (2019). Implikasi Kebijakan Bebas Visa Berdasarkan Peraturan Presiden Tentang Bebas Visa Kunjungan: Perspektif Ketenagakerjaan. Jurnal Ilmiah Kebijakan Hukum, 13(3), 311-322.

Setiawati, D. (2015). Penegakan Hukum Terhadap Warga Negara Asing (WNA) yang Melanggar Izin Tinggal 
Jurnal Preferensi Hukum

Vol. 2, No. 1, 2021

(Overstay). Journal Law, 10(14-29).

Soekanto, S. (2009). Penelitian Hukum Normatif. PT Raja Grafindo Persada.

Waluyo, B. (2002). Penelitian Hukum Praktek. Sinar Grafika.

Wirasto, W., Suhaidi, Siregar, M., \& Leviza, J. (2016). Pelaksanaan Pengawasan Warga Negara Asing di Wilayah Kerja Kantor Imigrasi Kelas II Belawan Berdasarkan UU No. 6 Tahun 2011 tentang Keimigrasian. USU Law Journal, 4(1), 168-185. 